Research Article

\title{
Anticorrosion Behaviour of Calcareous Deposits Formed on Steel Heat-Exchange Surfaces
}

\author{
Georgii Vasyliev (i) and Svitlana Vasylieva \\ National Technical University of Ukraine "Igor Sikorsky Kyiv Polytechnic Institute", 37, Prospect Peremohy, \\ Kyiv-56 03056, Ukraine \\ Correspondence should be addressed to Georgii Vasyliev; g.vasyliev@kpi.ua
}

Received 21 September 2019; Revised 25 December 2019; Accepted 2 January 2020; Published 21 January 2020

Academic Editor: Fernando Lusquiños

Copyright ( 92020 Georgii Vasyliev and Svitlana Vasylieva. This is an open access article distributed under the Creative Commons Attribution License, which permits unrestricted use, distribution, and reproduction in any medium, provided the original work is properly cited.

\begin{abstract}
A new electrode to study both scaling and corrosion processes of mild steel in tap water was developed. Two identical steel rings are placed on the outside of a glass tube which is heated from inside with an electric spiral; the rings are connected to a corrometer to form a two-electrode corrosion probe. The corrosion rate variations with scale thickness, scale deposition time, and solution composition are measured using the linear polarization resistance technique. The deposited scale was formed of calcite crystals of $50-100 \mu \mathrm{m}$ as established with SEM and XRD. The scale layer of $0.2 \mathrm{~mm}$ formed in tap water within 90 hours reduces the steel corrosion rate from 0.8 to $0.1 \mathrm{~mm} /$ year and serves as a barrier layer to prevent further corrosion.
\end{abstract}

\section{Introduction}

Scale and corrosion remain the most crucial problems of industrial heat-exchanging equipment [1-3]. Scale formation leads to heat losses and reduction of hydraulic pressure while corrosion causes fast shortening of the operation time. The formation of scale can lead to additional damage and increase of thermal fatigue [4]. The inhomogeneous accumulation of scale leads to the localization of corrosion processes and the formation of corrosion pits [5]. Equipment functioning in the scale and corrosion conditions requires regular clean-up and on-line water treatment, as well as more frequent equipment replacement due to corrosion losses. The expenses related to scale and corrosion problems cause billion dollars of losses [6-8]. The search for new efficient techniques to solve simultaneously scale and corrosion problems is both a challenging and actual task.

Promising approaches are based on water treatment with a complex reagent which enables prevention of both scaling and corrosion in heat exchangers $[9,10]$. The challenge of the task is that the scale and corrosion processes are reversely related: diminishing of scaling leads to corrosion aggression, whereas the dense scale layer reduces corrosion rate but causes high heat losses $[11,12]$. The selection of an optimal way of scale and corrosion reduction in industry is based on tedious laboratory investigations. For this purpose, different techniques are applied; however, their results often appear controversial.

The scaling tendency of water with added reagent is analysed by chemical methods considering changes in solution during the test. The model solution is thermostated at $80^{\circ} \mathrm{C}$, and the hardness salts concentration is titrated before and after the test [13]. The scaling tendency is calculated from the difference between the hardness contents before and after the test. The lower the difference, the higher the antiscaling efficiency of the reagent. The main drawback of this technique is that the properties of a heat-exchange surface towards scaling are ignored. The scale appearance is the result of change in water composition under heat; however the scale growth on the heat-exchange surface depends on the crystals' nucleation, their adhesion, and deposit removal [14].

To study the scale crystals growth on a surface, $\mathrm{pH}$ or carbonic equilibrium shift methods are applied [15-17]. Seed crystals are introduced to the saturated solution of calcium carbonate, and alkali is added drop-by-drop to induce 
crystallization. The amount of added alkali indicates the solution stability.

A more precise technique, electrocrystallization, applies electrochemical measurements [18-29]. A working electrode, which is usually made of steel, is polarized cathodically to a potential of $1.1 \mathrm{~V} / \mathrm{SCE}$ to cause oxygen reduction. The $\mathrm{pH}$ value of electrolyte adjacent to the steel surface is raised to 9.5, so that carbonic equilibrium is shifted to the formation of carbonates. Calcium carbonate precipitates thus reducing cathodic current. From the current-time dependence scaling, time and blocking properties of the layer can be estimated. While the method deals with both scaling potential of the solution and blocking properties of the scale layer, it works only until the bare surface of the electrode is fully covered. Further growth of the scale layer is not possible.

An efficient experimental procedure that estimates both bulk and surface scaling coupled with corrosion rate measurements is highly desired [30]. The aim of the present work was to develop a simple technique to study temperature scaling and corrosion rate variations of mild steel under the scale layer. To this aim, a working electrode (Figure 1), which models a heat-exchange surface, has been designed that enables instantaneous corrosion rate determination during the scale deposition.

\section{Experiment}

2.1. Working Electrode Construction. A scheme of the working electrode is given in Figure 1. Its body was made of Pyrex glass tube (1) of $8 \mathrm{~mm}$ diameter. A heating spiral (2) made of a $0.3 \mathrm{~mm}$ nichrome wire was placed inside the glass tube. The electrical resistance of the spiral was $8 \mathrm{Ohm}$. The space between the wire and inner glass wall was filled with $2-4 \mu \mathrm{m} \mathrm{SiO}_{2}$ powder (3) to achieve better heat transfer between the spiral and the glass wall. A pair of identical steel rings (4) (10 $\mathrm{mm}$ length and $19 \mathrm{~mm}$ in diameter) were placed coaxially on the outer wall of the glass tube. Mild steel St3 (European analogue of $\mathrm{Fe}_{3} \mathrm{CN}$ ) containing $0.20 \% \mathrm{C}, 0.43 \%$ $\mathrm{Mn}, 0.23 \% \mathrm{Si}, 0.016 \% \mathrm{~S}$, and $0.02 \% \mathrm{P}$ was used as a material for the rings. The heating spiral was connected to the current transformer with the output voltage of $24 \mathrm{~V}$, electrical power of a spiral was $72 \mathrm{~W}$, and heat load of the electrode was $60 \mathrm{~kW} / \mathrm{m}^{2}$.

2.2. Experimental Procedure. The steel rings surface was mechanically polished with $\mathrm{SiC}$ emery paper of P600 grade, degreased with organic solvent, and rinsed with tap and distilled water. The working electrode was placed inside a glass beaker of 11 , filled with water solution. The beaker was closed on the top with a teflon cover, and a reverse cooler was placed in the cover to prevent solution evaporation during the experiment. A thermometer was also placed on the top of the teflon cover in order to monitor temperature variations during the test. The working electrode heated the solution with its heating spiral. After approximately 3 hours, the water in the beaker reached the temperature of $100^{\circ} \mathrm{C}$ and started boiling, and the electrode working conditions were

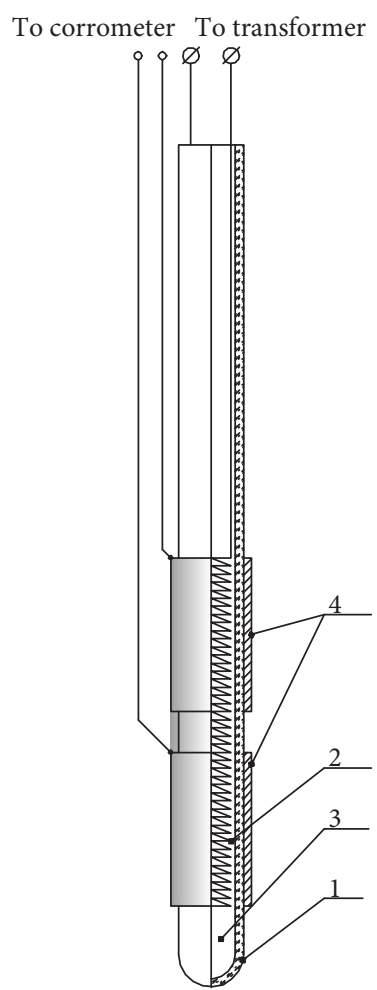

Figure 1: The scheme of the electrode to study scaling and corrosion processes: 1 , pyrex glass tube; 2 , heating spiral; $3, \mathrm{SiO}_{2}$ powder; and 4, steel rings.

reached. The test continued for 6 hours; afterwards, heating was turned off, and the water was replaced with a fresh portion to keep hardness salts concentration constant. The procedure was repeated daily. The total boiling duration reached 100 hours. All the tests were performed in tap water, and its composition is given in Table 1.

The hardness salts content was determined titrometrically before and after the test as total concentration of calcium and magnesium ions expressed as calcium carbonate. A solution sample was buffered to $\mathrm{pH} 10.1$, the indicator was added, and ethylenediaminetetraacetic disodium salt (EDTA) was used as the titrant. The total dissolved solids content was determined with a TDS-meter based on conductivity measurements. The $\mathrm{pH}$ value of the solution was measured using an I-160MI pH-meter.

2.3. Scale Characterization. The linear polarization resistance technique (LPR) was used for corrosion [31-33]. A pair of the steel rings were electrically connected to a corrometer R5126 (Ukrainian manufacture) and served as a two-electrode corrosion probe. LPR measurements were performed every $15 \mathrm{~min}$.

The corrometer utilizes galvanostatic polarization mode: the current density of $5 \mu \mathrm{A} / \mathrm{cm}^{2}$ is applied during $30 \mathrm{sec}$ to the pair of the electrodes [34]. The initial potential difference and solution resistance were automatically compensated, and the polarization resistance value was recalculated into steel corrosion rate with Stern's equation using the conventional $B$ value of $26 \mathrm{mV}$ [35]. The B value of $26 \mathrm{mV}$ was 
TABle 1: Water chemical composition.

\begin{tabular}{|c|c|c|c|}
\hline \multicolumn{2}{|c|}{ Parameter } & \multirow[t]{2}{*}{ Units } & \multirow{2}{*}{$\begin{array}{c}\text { Value } \\
7.8-8.0\end{array}$} \\
\hline $\mathrm{pH}$ & & & \\
\hline Dissolved oxygen & $\mathrm{DO}$ & $\mathrm{mg} / \mathrm{l}$ & 6.0 \\
\hline Total hardness & $\mathrm{TH}$ & $\mathrm{mmol} / \mathrm{l}$ & $3.9-4.2$ \\
\hline Total alkalinity & TA & $\mathrm{mmol} / \mathrm{l}$ & $3.9-4.1$ \\
\hline Calcium & $\mathrm{Ca}^{2+}$ & $\mathrm{mmol} / \mathrm{l}$ & $3.0-3.1$ \\
\hline Magnesium & $\mathrm{Mg}^{2+}$ & $\mathrm{mmol} / \mathrm{l}$ & $0.9-1.1$ \\
\hline Chloride & $\mathrm{Cl}^{-}$ & $\mathrm{mg} / \mathrm{l}$ & $18-25$ \\
\hline Sulfate & $\mathrm{SO}_{4}^{2-}$ & $\mathrm{mg} / \mathrm{l}$ & $30-35$ \\
\hline Hydrocarbonate & $\mathrm{HCO}_{3}^{-}$ & $\mathrm{mmol} / \mathrm{l}$ & $3.2-3.5$ \\
\hline Total dissolved solids & TDS & $\mathrm{mg} / \mathrm{l}$ & $240-260$ \\
\hline
\end{tabular}

chosen because in the experimental conditions, the steel corrodes with oxygen depolarization and oxygen supply to the surface determines the corrosion rate.

The scale growth rate during its deposition was characterised by the scale thickness. Every 20-40 hours of boiling, the diameters of the steel rings were measured using a micrometer MK-25 with $0.01 \mathrm{~mm}$ accuracy.

The X-ray diffraction phase analysis (XRD) of the scale deposits was performed using a Shimandzu LabX XRD 6000 powder X-ray diffractometer. Full X-ray diffraction patterns were recorded for the scan angles $(2 \theta)$ from 5 to $90^{\circ}$ with a step size of $0.1^{\circ}$. By using the ICDD-PDF database, individual crystalline phases were identified from their observed XRD patterns. The morphology of the surface was studied with the use of a SEM-106I Selmi microscope (Ukraine) operated at $20 \mathrm{kV}$.

\section{Results and Discussion}

The typical time dependence of the temperature and water parameters is presented in Figure 2. Water temperature rises during the first 3 hours and remains constant when the water is boiling (Figure 2(d)). It is clearly seen that the major hardness salts deposition occurs between 1.5 and 4.5 hours of heating (Figure 2(d)). The deposition starts when the water temperature reaches $70^{\circ} \mathrm{C}$ and continuous while hardness salts are present in the water. However, it is not reasonable to continue the experiment after 6 hours, because the crystallization rate becomes very low. After this period, further boiling does not change water hardness appreciably meaning all available carbonates are deposited. At this point, the solution should be replaced with a fresh one. The same results are obtained with TDS measuring during the test (Figure 2(c)). Comparing the TDS and total hardness dependences vs. time, it can be clearly seen that the calcium carbonate is the only precipitate in these conditions. The $\mathrm{pH}$ of the water (Figure 2(b)) rises during the first 4.5 hours, due to $\mathrm{CO}_{2}$ desorption from the water. When the main part of $\mathrm{CaCO}_{3}$ is deposited, $\mathrm{pH}$ value becomes constant.

The scale thickness vs. time is given in Figure 3, curve 1. The deposition of hardness salts results in scale formation on the electrode surface. The surface scale layer grows steadily $(21 \mu \mathrm{m} / \mathrm{h})$ during the test meaning the scaling conditions remain constant. The deposition of carbonate scale forms a barrier layer on the electrode surface reducing oxygen ingress and so steel corrosion rate (Figure 3, curve 2). When a freshly prepared steel surface was immersed in tap water, the corrosion rate reached significant values up to $0.8 \mathrm{~mm} /$ year. After the first 20 hours of boiling, the corrosion rate starts decreasing and finally stabilizes below $0.1 \mathrm{~mm} /$ year in 70 hours. Further scale deposition does not cause any further corrosion rate reduction.

The rate of steel corrosion in tap water is known to be controlled by the rate of oxygen diffusion to the surface. When a freshly prepared steel surface is immersed into the solution, the corrosion rate is high. As scale deposition progresses, the scale crystals partially cover the surface and the oxygen ingress to the covered parts is limited. Thus, corrosion rate decreases. The size and morphology of single scale crystals are determined by water composition and scaling rate, while the number of crystal nuclei is determined by the surface roughness. After the initial nuclei are formed on the surface, further scale growth occurs on these crystals and appearance of new crystallization sites is less probable. When all the surfaces are covered with scale crystals of finite size, some pores remain and corrosion continues, but the corrosion rate is significantly lower.

The formation of a sediment layer on the metal surface is known to influence the corrosion process. As investigated for the $316 \mathrm{~L}$ and ND steels in the conditions of a gas deep cooling device operation, the metal surface was covered by an ash deposit layer, coupling layer, and corrosion layer. Layered structure of the deposits leads to the accumulation of the acids in the resurface layer, and the corrosion rate rises significantly, especially when the wall temperature is lower than the dew point $[36,37]$. Such mechanism is not relevant to the corrosion in fluids; however, the formation of a nonuniform scale layer may lead to the localization of corrosion. Parts of the surface, covered with scale crystals, become anodic, and in meantime, pores in the scale layer supply oxygen to the surface and regions near the pores become cathodic. The pairs of differential aeration occur, accelerating local metal dissolution under the scale crystals. In order to prevent localization of corrosion process, the scale layer needs to be thin and uniform. The formation of such a protective layer is the aim of our further investigations.

The morphology of the formed scale layer was investigated with SEM (Figure 4). The rings surface is fully covered with calcite crystals easily recognisable by their 


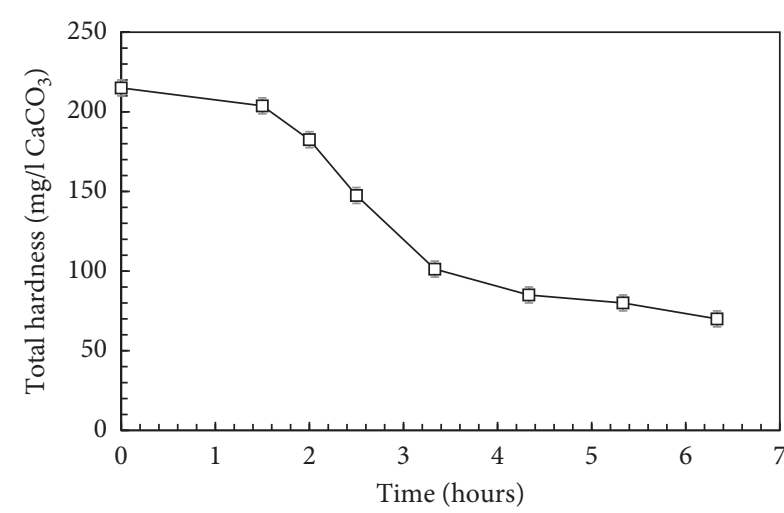

(a)

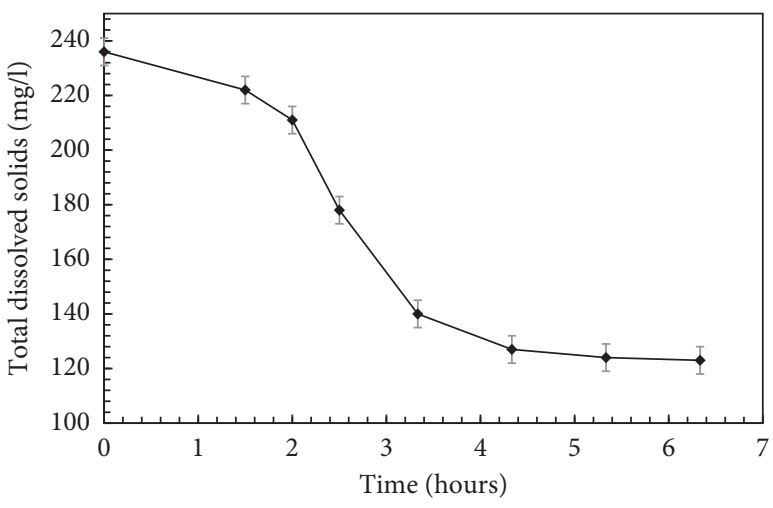

(c)

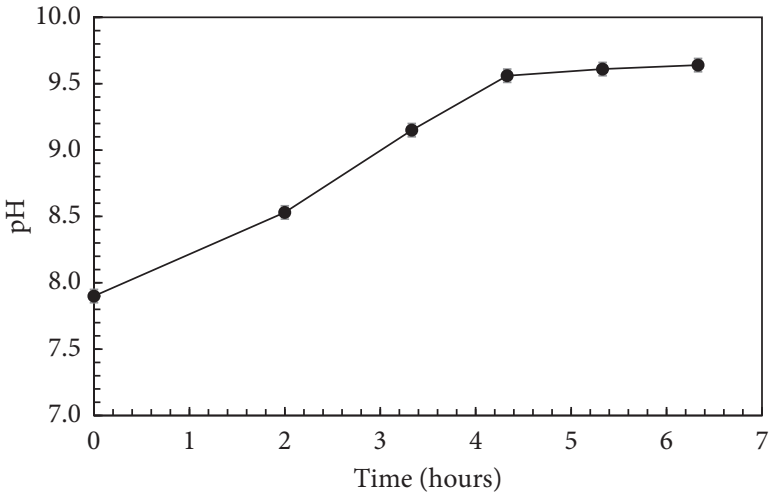

(b)

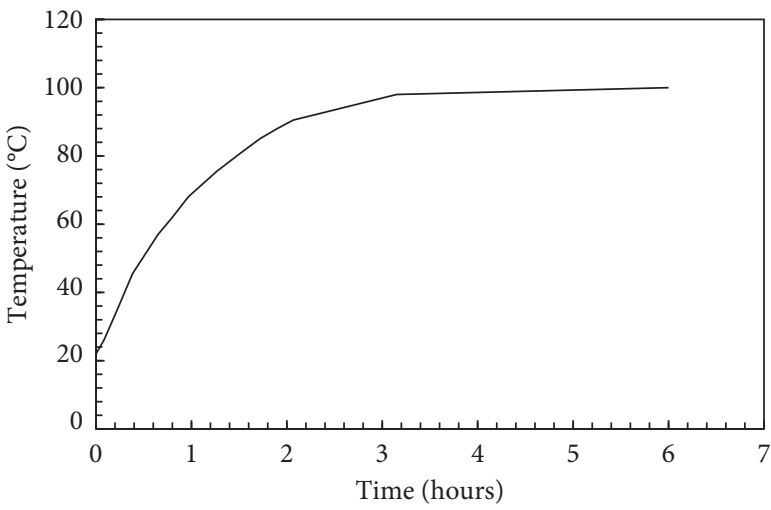

(d)

FIGURE 2: Solution parameters variation during daily run.

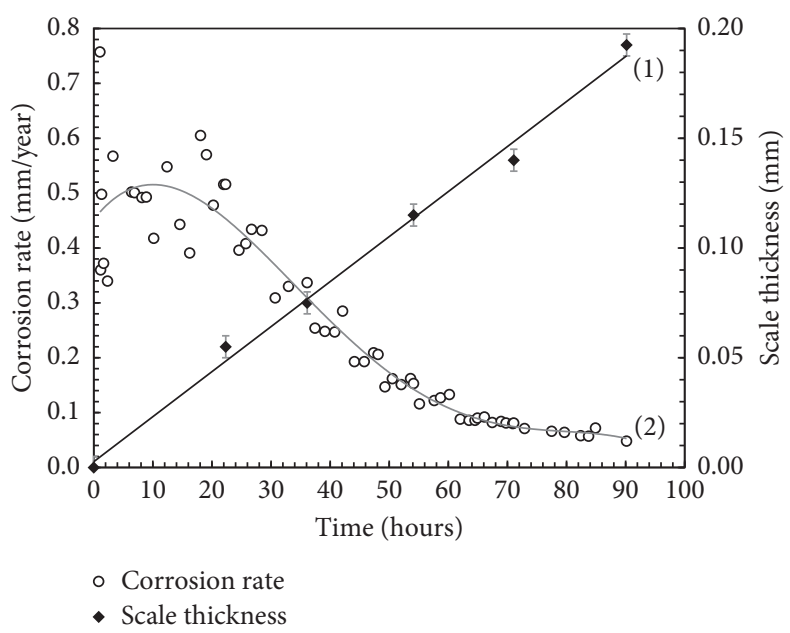

FIgURE 3: Scale thickness (1) and LPR corrosion rate (2) vs. time for the steel surface boiling in tap water solution.

rhombohedral shape. The growth of the crystals is spontaneous, and no specific directions are found. Crystals are grouped in agglomerates with the size of $50-100 \mu \mathrm{m}$.

The crystalline structure of calcite was confirmed with XRD (Figure 5). The XRD pattern clearly demonstrates characteristic peaks of calcite according to JCPDS PDF2 standard card (01-086-2335). The deposition of calcite occurs on a partially corroded metal surface because the corrosion rate on freshly prepared steel is high. When the surface is covered with the scale layer, scale growth rate becomes constant and no changes in the layer structure are observed.

The presence of $\mathrm{Mg}$ is detected in the crystals because of magnesium incorporation into the calcite lattice [38]. Incorporation of magnesium in the calcite crystals changes their morphology and crystals become damaged and nonuniform. $\mathrm{Mg}^{2+}$ ions are known to adsorb on the growing sites of the calcite crystal, thus blocking its regular growth. 

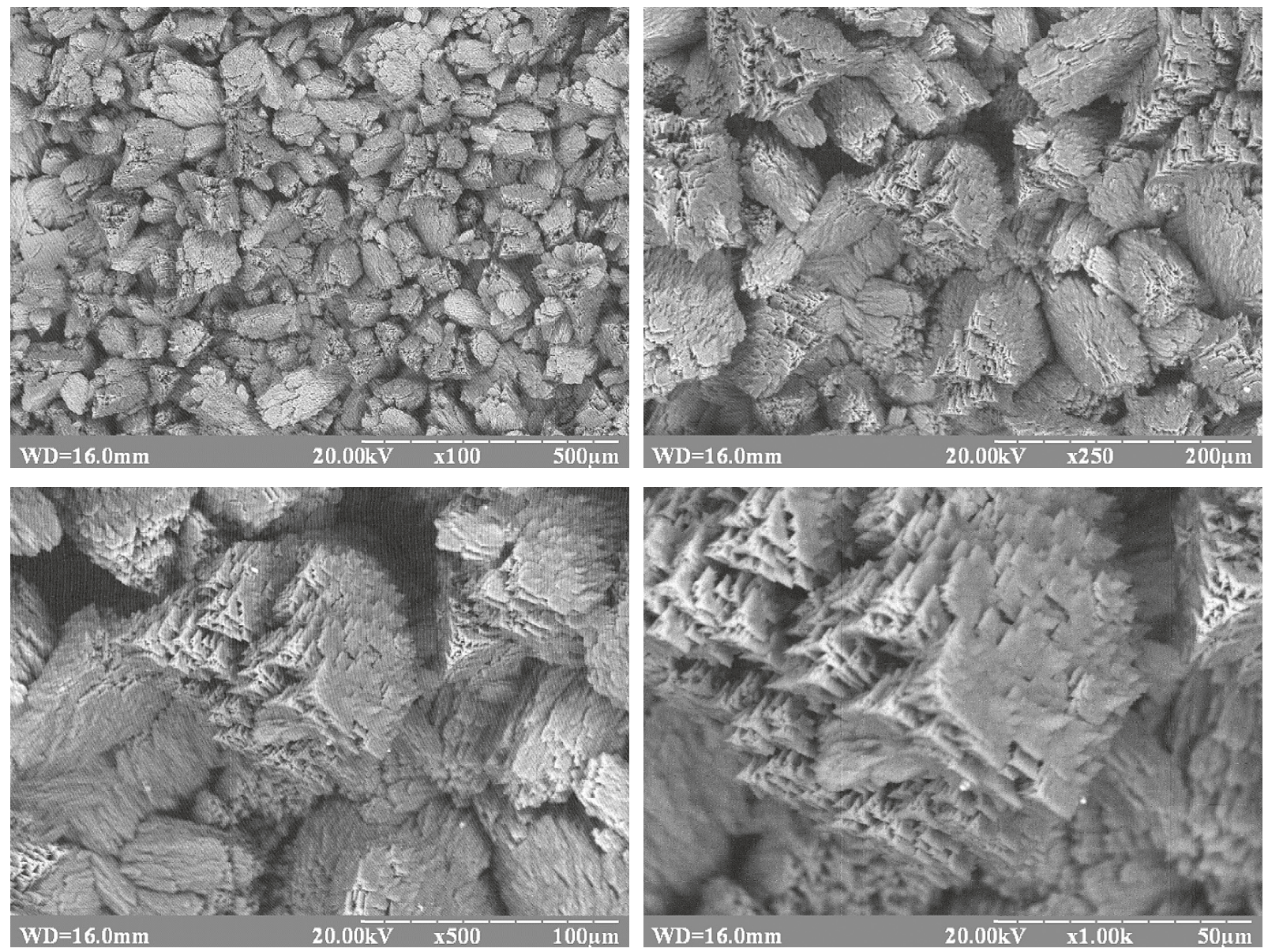

FIgURE 4: SEM images of the scaled surface after 100 hours of boiling in tap water solution.

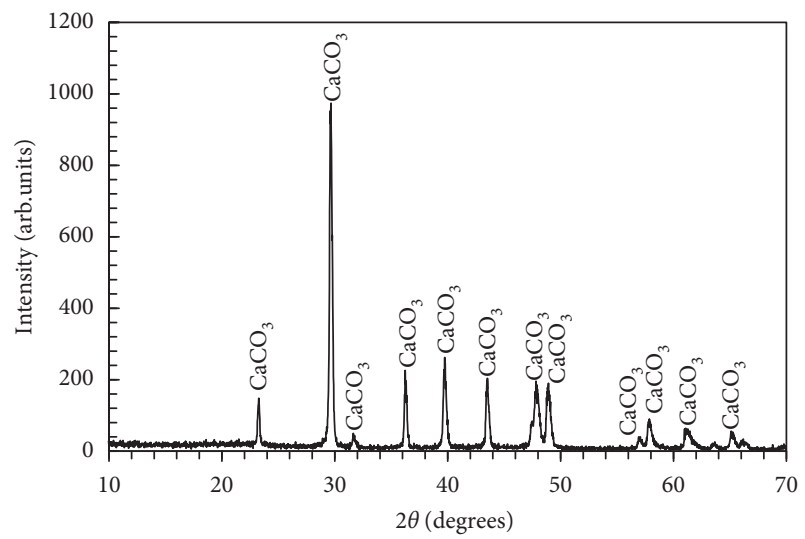

FIGURE 5: XRD of the scaled surface after 100 hours of boiling in tap water solution.

The scale layer appears to be an efficient barrier on the steel surface, being able to suppress oxygen diffusion and thus to reduce corrosion rate. Such a barrier can play a significant role in corrosion prevention in industrial equipment that operate in the scaling conditions; however, excess scale thickness impedes heat transfer and flow rate. The designed working electrode successfully models a heat-exchanger surface and is a convenient tool to study both scaling and corrosion processes. Its use allows studying the dependence of steel corrosion rate on scale morphology and thickness. The main advantage of the proposed electrode design is that scaling continues when the electrode surface is fully covered with the scale crystals. This gives a possibility to study controllable scale removal and its influence on corrosion rate.

\section{Conclusions}

A simple and reliable technique to study scale formation and corrosion processes concurrently on the steel surface has been developed. The designed working electrode can be used both in laboratory and in industry to determine the scale and corrosion inhibitors efficiency.

The developed electrode and technique were used to establish the protection properties of a scale layer on the steel surface. The scale layer of $0.2 \mathrm{~mm}$ formed from tap water reduces the corrosion rate from 0.8 to $0.1 \mathrm{~mm} /$ year in 100 hours and can serve natural corrosion protection.

The developed technique can be further used to investigate the influence of the scale removal processes on corrosion of steel heat-exchange surfaces.

\section{Data Availability}

The LPR and XRD data used to support the findings of this study are included within the article. 


\section{Conflicts of Interest}

The authors declare that they have no conflicts of interest.

\section{Acknowledgments}

This work was supported by the Ministry of Education and Science of Ukraine (grant no. 2044, 2017). The author would like to thank Prof. Y. Gerasymenko (National technical university of Ukraine "Igor Sikorsky Kyiv Polytechnic Institute") for helpful discussion.

\section{References}

[1] F. Smaïli, V. S. Vassiliadis, and D. I. Wilson, "Optimization of cleaning schedulesin heat exchanger networkssubject to fouling," Chemical Engineering Communications, vol. 189, no. 11, pp. 1517-1549, 2002.

[2] M. Li, C. Dai, B. Yang, Y. Qiao, and Z. Zhu, "New and green multi-component scaling and corrosion inhibitor for the cooling water of central air conditioners," Journal of Materials Engineering and Performance, vol. 26, no. 2, pp. 764-772, 2017.

[3] H. Ashassi-Sorkhabi, E. Asghari, and M. Mohammadi, "Effects of solution hydrodynamics on corrosion inhibition of steel by citric acid in cooling water," Journal of Materials Engineering and Performance, vol. 23, no. 8, pp. 2992-3000, 2014.

[4] P. Yasniy, P. Maruschak, R. Bishchak, V. Hlado, and A. Pylypenko, "Damage and fracture of heat resistance steel under cyclic thermal loading," Theoretical and Applied Fracture Mechanics, vol. 52, no. 1, pp. 22-25, 2009.

[5] P. O. Maruschak, A. P. Sorochak, and O. V. Maruschak, "Fractodiagnostics of reasons of degradation and failure of steel water pipes," in Proceedings of the 16-th International Conference "Transport Means", pp. 183-186, Kaunas University of Technology, Palanga, Lithuania, October 2012.

[6] E. F. C. Somerscales, "Fundamentals of corrosion fouling," Experimental Thermal and Fluid Science, vol. 14, no. 4, pp. 335-355, 1997.

[7] J. Liang, A. Deng, R. Xie et al., "Impact of flow rate on corrosion of cast iron and quality of re-mineralized seawater reverse osmosis (SWRO) membrane product water," Desalination, vol. 322, pp. 76-83, 2013.

[8] M. Chaussemier, E. Pourmohtasham, D. Gelus et al., "State of art of natural inhibitors of calcium carbonate scaling. A review article," Desalination, vol. 356, pp. 47-55, 2015.

[9] D.-J. Choi, S.-J. You, and J.-G. Kim, "Development of an environmentally safe corrosion, scale, and microorganism inhibitor for open recirculating cooling systems," Materials Science and Engineering: A, vol. 335, no. 1-2, pp. 228-235, 2002.

[10] D. Hasson, H. Shemer, and A. Sher, "State of the art of friendly "green" scale control inhibitors: a review article," Industrial \& Engineering Chemistry Research, vol. 50, no. 12, pp. 76017607, 2011.

[11] Q. Yang, Y. Liu, A. Gu, J. Ding, and Z. Shen, "Investigation of induction period and morphology of $\mathrm{CaCO}_{3}$ fouling on heated surface," Chemical Engineering Science, vol. 57, no. 6, pp. 921-931, 2002.

[12] N. Andritsos and A. J. Karabelas, "Calcium carbonate scaling in a plate heat exchanger in the presence of particles," International Journal of Heat and Mass Transfer, vol. 46, no. 24, pp. 4613-4627, 2003.
[13] NACE International, TM0374 Laboratory Screening Tests to Determine the Ability of Scale Inhibitors to Prevent the Precipitation of Calcium Sulfate and Calcium Carbonate from Solution (For Oil and Gas Production Systems), NACE International, Houston, TX, USA, 2016.

[14] H. Müller-Steinhagen, "Cooling-water fouling in heat exchangers," Advances in Heat Transfer, vol. 33, pp. 415-496, 1999.

[15] Y. Zhang and R. A. Dawe, "Influence of $\mathrm{Mg}^{2+}$ on the kinetics of calcite precipitation and calcite crystal morphology," Chemical Geology, vol. 163, no. 1-4, pp. 129-138, 2000.

[16] Y.-P. Lin and P. C. Singer, "Effect of $\mathrm{Mg}^{2+}$ on the kinetics of calcite crystal growth," Journal of Crystal Growth, vol. 312, no. 1, pp. 136-140, 2009.

[17] J.-Y. Gal, Y. Fovet, and N. Gache, "Mechanisms of scale formation and carbon dioxide partial pressure influence. Part I. Elaboration of an experimental method and a scaling model," Water Research, vol. 36, no. 3, pp. 755-763, 2002.

[18] J. Marín-Cruz, E. Garćia-Figueroa, M. Miranda-Hernández, and I. González, "Electrochemical treatments for selective growth of different calcium carbonate allotropic forms on carbon steel," Water Research, vol. 38, no. 1, pp. 173-183, 2004.

[19] J. Marín-Cruz, R. Cabrera-Sierra, M. A. Pech-Canul, and I. González, "Characterization of different allotropic forms of calcium carbonate scales on carbon steel by electrochemical impedance spectroscopy," Journal of Applied Electrochemistry, vol. 34, no. 3, pp. 337-343, 2004.

[20] G. S. Vasyliev and S. M. Vasylieva, "The influence of ultrasound on the carbonate cathodic crystallization in artificial potable water," Journal of the Electrochemical Society, vol. 164, no. 4, pp. H250-H256, 2017.

[21] G. Vasyliev, S. Vasylieva, A. Novosad, and Y. Gerasymenko, "Ultrasonic modification of carbonate scale electrochemically deposited in tap water," Ultrasonics Sonochemistry, vol. 48, pp. 57-63, 2018.

[22] A. Neville and A. P. Morizot, "Electrochemical assessment of calcium carbonate deposition using a rotating disc electrode (RDE)," Journal of Applied Electrochemistry, vol. 29, no. 4, pp. 455-462, 1999.

[23] C. Barchiche, C. Deslouis, O. Gil, S. Joiret, P. Refait, and B. Tribollet, "Role of sulphate ions on the formation of calcareous deposits on steel in artificial seawater; the formation of green rust compounds during cathodic protection," Electrochimica Acta, vol. 54, no. 13, pp. 3580-3588, 2009.

[24] A. R. Rakitin and V. I. Kichigin, "Electrochemical study of calcium carbonate deposition on iron. Effect of the anion," Electrochimica Acta, vol. 54, no. 9, pp. 2647-2654, 2009.

[25] C. Barchiche, C. Deslouis, O. Gil, P. Refait, and B. Tribollet, "Characterisation of calcareous deposits by electrochemical methods: role of sulphates, calcium concentration and temperature," Electrochimica Acta, vol. 49, no. 17-18, pp. 2833-2839, 2004.

[26] A. Neville and A. P. Morizot, "Calcareous scales formed by cathodic protection-an assessment of characteristics and kinetics," Journal of Crystal Growth, vol. 243, no. 3-4, pp. 490-502, 2002.

[27] C. Gabrielli, G. Maurin, G. Poindessous, and R. Rosset, "Nucleation and growth of calcium carbonate by an electrochemical scaling process," Journal of Crystal Growth, vol. 200, no. 1-2, pp. 236-250, 1999.

[28] Z. Belarbi, J. Gamby, L. Makhloufi, and B. Tribollet, "Nucleation-growth process of calcium carbonate on rotating disk electrode in mineral potable water," Electrochimica Acta, vol. 109, pp. 623-629, 2013. 
[29] Y. Ben Amor, L. Bousselmi, M.-C. Bernard, and B. Tribollet, "Nucleation-growth process of calcium carbonate electrodeposition in artificial water-Influence of the sulfate ions," Journal of Crystal Growth, vol. 320, no. 1, pp. 69-77, 2011.

[30] L. Sanders, X. Hu, E. Mavredaki, V. Eroini, R. Barker, and A. Neville, "Assessment of combined scale/corrosion inhibitors-a combined jar test/bubble cell," Journal of Petroleum Science and Engineering, vol. 118, pp. 126-139, 2014.

[31] R. Kelly, Electrochemical Techniques in Corrosion Science and Engineering, CRC Press, Boca Raton, FL, USA, 2002.

[32] Y. S. Herasymenko and H. S. Vasylev, "A two-step method for the evaluation of corrosion rate in metals," Materials Science, vol. 45, no. 6, pp. 899-904, 2009.

[33] H. S. Vasylev and Y. S. Herasymenko, "Corrosion meters of new generation based on the improved method of polarization resistance," Materials Science, vol. 52, no. 5, pp. 722-731, 2017.

[34] H. S. Vasylev, "Measurement of polarization resistance with computer logging of results," Materials Science, vol. 48, no. 5, pp. 694-696, 2013.

[35] F. Mansfeld, The Polarization Resistance Technique for Measuring Corrosion Currents, Springer US, Berlin, Germany, 1976.

[36] Y. Wang, H. Ma, Z. Liang, H. Chen, Q. Zhao, and X. Jin, "Experimental study on dew point corrosion characteristics of the heating surface in a $65 \mathrm{t} / \mathrm{h}$ biomass-fired circulating fluidized bed boiler," Applied Thermal Engineering, vol. 96, pp. 76-82, 2016.

[37] Z. Y. Liang, Q. X. Zhao, Y. G. Wang, Y. X. Li, and Z. C. Zhang, "Coupling mechanism of dew point corrosion and viscous ash deposits," Materials and Corrosion, vol. 65, no. 8, pp. 797-802, 2014.

[38] Y. Ben Amor, L. Bousselmi, B. Tribollet, and E. Triki, "Study of the effect of magnesium concentration on the deposit of allotropic forms of calcium carbonate and related carbon steel interface behavior," Electrochimica Acta, vol. 55, no. 16, pp. 4820-4826, 2010. 


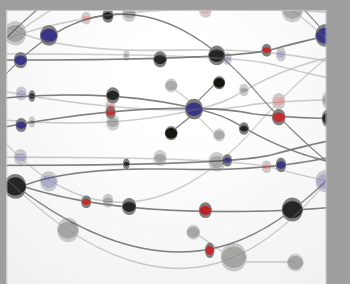

The Scientific World Journal
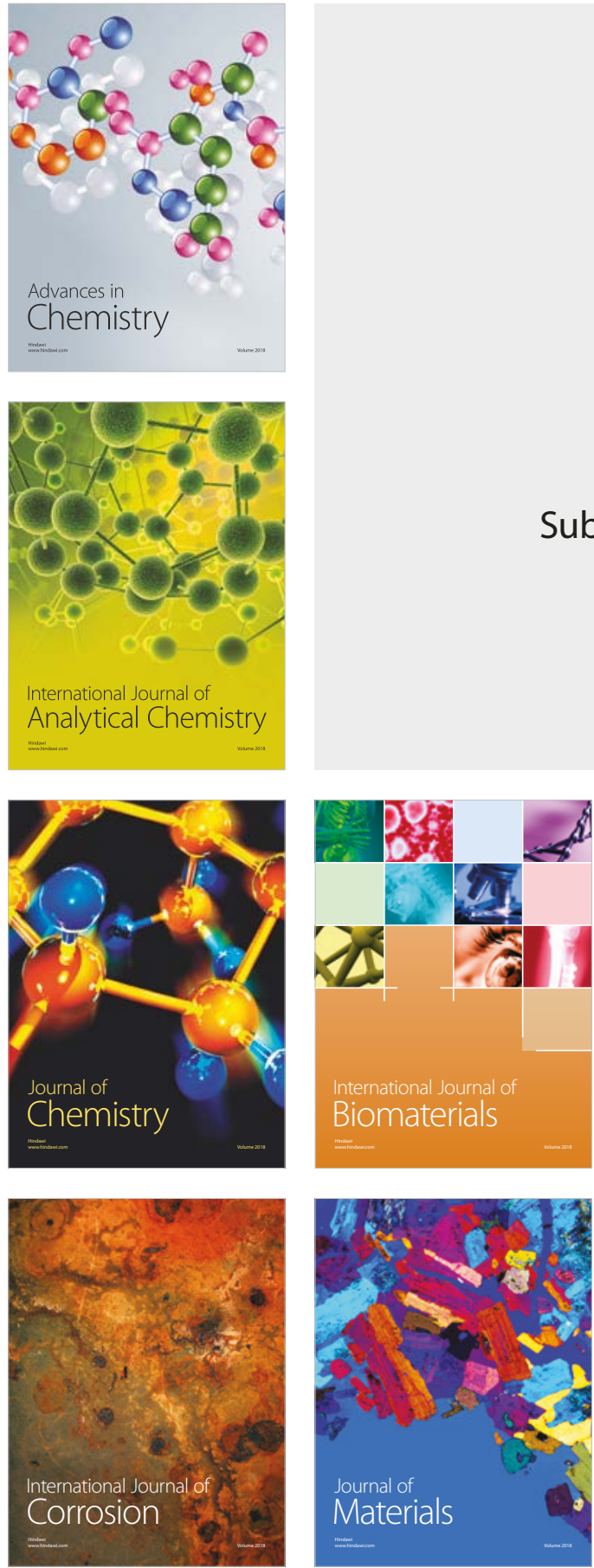

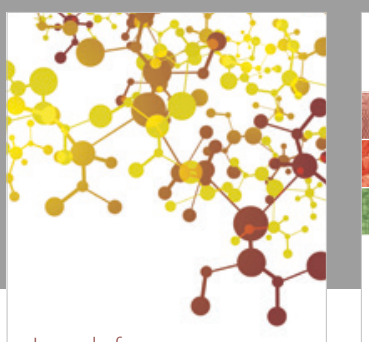

Journal of

Applied Chemistry
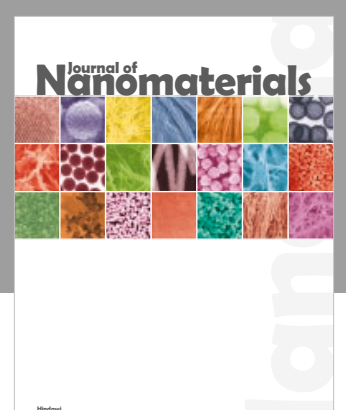

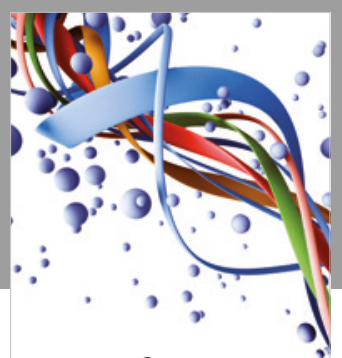

Scientifica

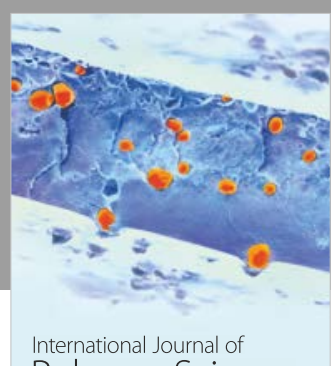

Polymer Science

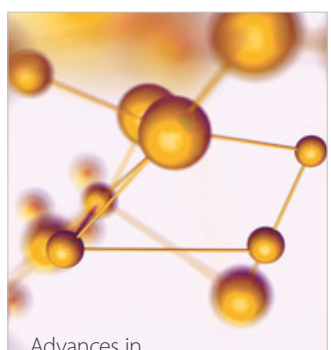

Physical Chemistry
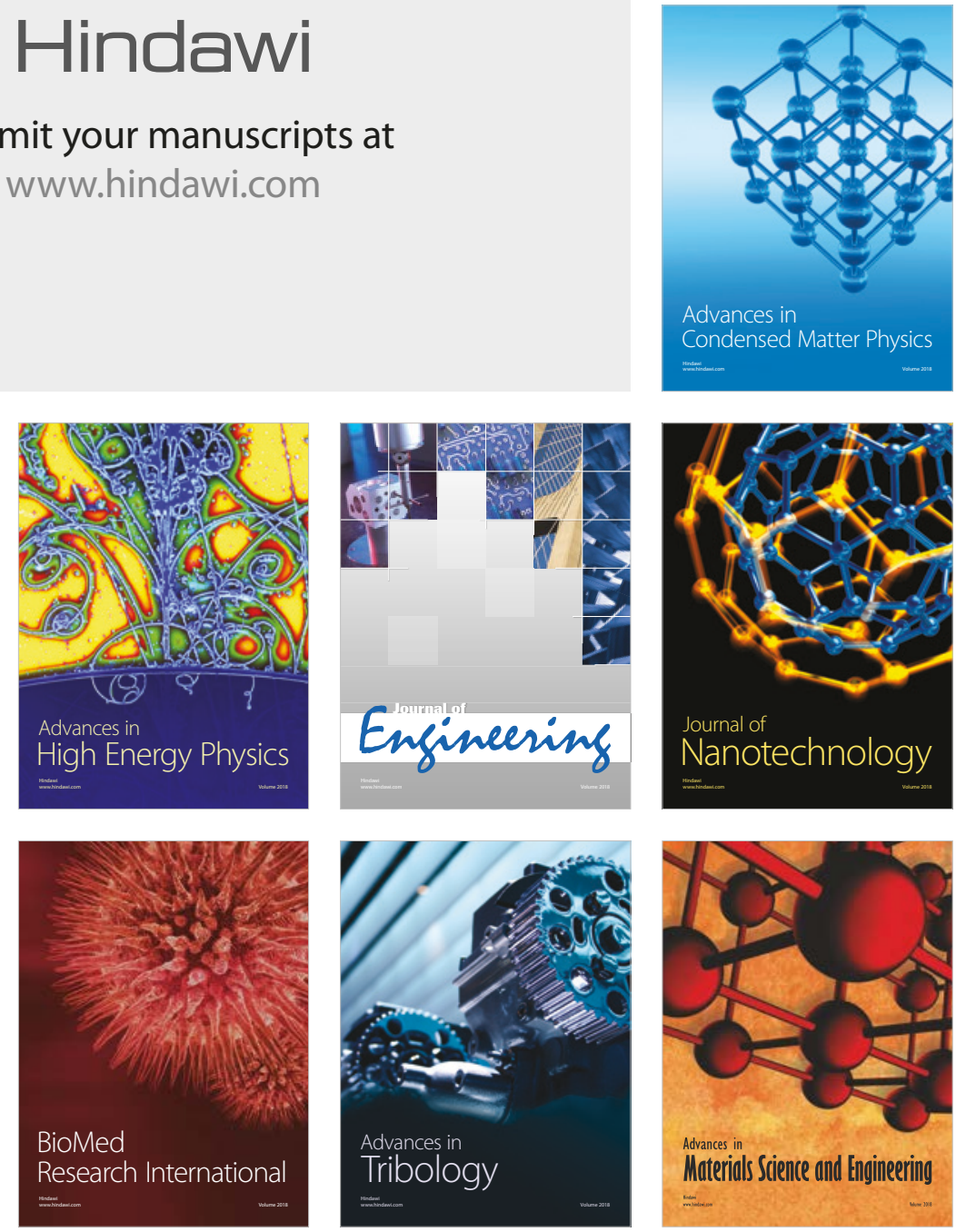